\title{
New insights on hepatocellular carcinoma: epidemiology and clinical aspects
}

\author{
Claudio Puoti \\ Liver Unit, INI Research Institute and Clinics Grottaferrata, Rome 00046, Italy. \\ Correspondence to: Dr. Claudio Puoti, Liver Unit, INI Research Institute and Clinics Grottaferrata, Rome, Italy. \\ Email address: puoti@epatologia.org
}

How to cite this article: Puoti C. New insights on hepatocellular carcinoma: epidemiology and clinical aspects. Hepatoma Res 2018;4:57. http://dx.doi.org/10.20517/2394-5079.2018.67

Received: 25 May 2018 First Decision: 17 Jul 2018 Revised: 29 Jul 2018 Accepted: 1 Aug 2018 Published: 21 Sep 2018

Science Editor: Guang-Wen Cao Copy Editor: Cai-Hong Wang Production Editor: Zhong-Yu Guo

\begin{abstract}
Primary liver cancer represents the 4 th most common tumor in males (4\% of all cancers) and the 7 th most common tumor in females (2.3\% of all cancers), with a prevalence of 53/100,000 in males and $22 / 100,000$ in females (male-to-female ratio $=2: 1$ ). In the majority of the cases, hepatocellular carcinoma $(H C C)$ develops in patients with cirrhosis and thus the risk factors for HCC and chronic liver disease are overlapping. Viral infections (hepatitis B virus, hepatitis C virus), alcohol and fat (nonalcoholic fatty liver disease/non-alcoholic steatohepatitis) represent the main risk factors for development of HCC on cirrhotic liver. Several prospective studies reported that at present $\mathrm{HCC}$ does represent the first cause of death of cirrhotic patients, while in the past morbidity and mortality in cirrhosis were mainly determined by other non-neoplastic complications of the disease. From a clinical point of view, staging systems in HCC should define outcome prediction and treatment assignment. Due to the nature of HCC, the main prognostic variables are the tumor stage, liver function and performance status. The most accepted clinical classification of HCC has been proposed by the Barcelona Clinic Liver Cancer. The BCLC staging system has come to be widely accepted in clinical practice and is also being used for many clinical trials of new drugs to treat HCC. Therefore, it has become the de facto staging system that is used.
\end{abstract}

Keywords: Alcohol, cirrhosis, hepatitis B virus, hepatocellular carcinoma, hepatitis C virus, non-alcoholic steatohepatitis

\section{INTRODUCTION}

Hepatocellular carcinoma (HCC) represents one of the most common human neoplasm, being one of the leading mortality worldwide ${ }^{[1,2]}$. The main feature of HCC consists in that it affects mostly patients with liver

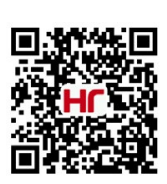


cirrhosis, often of viral [hepatitis B virus (HBV), hepatitis C virus (HCV)] or dysmetabolic origin; it means that subjects with HCC suffer from three distinct diseases: the cancer, the cirrhosis and the virus, making more difficult the clinical management of these people.

Indeed, it is known that the mechanisms of hepatocarcinogenesis result from the combination of several causes, such as genetic, immunological, virus-related, environmental and host factors. Host-related factors include male gender, age of at least 50 years, family predisposition, obesity, advanced liver fibrosis or cirrhosis and co-infection with other hepatotropic viruses and human immunodeficiency virus. Environmental factors include heavy alcohol abuse, cigarette smoking, and exposure to aflatoxin ${ }^{[3]}$.

From a clinical point of view, it should be considered that these people, often critically ill individuals, often elderly, may suffer from clinically relevant abnormalities of haemostasis, renal function and electrolyte balance, and finally often suffer from systemic diseases (heart, lung).

At present HCC does represent the first cause of death of cirrhotic patients ${ }^{[2]}$, while in the past morbidity and mortality in cirrhosis were mainly determined by other complications of the disease, such as hepatic encephalopathy, upper digestive bleeding from esophageal varices, spontaneous bacterial peritonitis and hepatorenal syndrome. This is mainly due to both early diagnosis and optimized treatment of non-oncologic complications, that increasing life expectancy might be in parallel with the increase of the HCC incidence.

This review is aimed at analyzing available data on the epidemiology and on the clinical aspects of HCC, focusing on the current knowledge about the management of the disease.

\section{EPIDEMIOLOGY}

Available international epidemiological data show that primary liver cancer represents the 7th most common tumor in males ( $4 \%$ of all cancers) and the 13 th most common tumor in females ( $2.3 \%$ of all cancers), with a prevalence of 53/100,000 in males and 22/100,000 in females (male-to-female ratio $=2: 1)^{[1,2]}$. The lifetime (up to 74 years of age) risk of diagnosis of HCC is $17 \%$ in men $(1 / 59)$ and $5 \%$ in women (1/199). Primary liver cancer is the 5th cause of mortality in men (3rd in subjects 50-69 years old) and the 7 th in women (4.5\% of malignancy-related mortality $)^{[4,5]}$.

Anyway, relevant geographical differences exist. In Chinese and in African populations, the mean age of patients with the tumor is appreciably younger. This is in sharp contrast to Japan, where the incidence of HCC is the highest in the cohort of men aged 70-79 years. The pattern of HCC occurrence has a clear geographical distribution, with the highest incidence rates in East Asia, sub-Saharan Africa, and Melanesia, where around $85 \%$ of cases occur. In developed regions, the incidence is low with the exception of Southern Europe where the incidence in men is significantly higher than in other developed regions ${ }^{[2]}$.

There is a growing incidence of HCC worldwide. Overall, the incidence and mortality rates were of 65,000 and 60,240 cases in Europe and 21,000 and 18,400 cases in the United States in 2008, respectively. It is estimated that by 2020 the number of cases will reach 78,000 and 27,000 , respectively ${ }^{[2]}$.

Several factors are known to be associated with a higher incidence of HCC: (1) male gender; (2) increasing age; (3) environmental and geographic factors; (4) metabolic and genetic factors (e.g., non-alcoholic steatohepatitis (NASH), genetic hemochromatosis); (5) viral infection; (6) alcohol intake; (7) oncogenic factors (e.g., aflatoxin); and (8) histological stage.

In the majority of the cases, HCC develops in patients with cirrhosis and thus the risk factors for HCC and 
chronic liver disease are overlapping ${ }^{[1]}$. From a clinical point of view, it means that most of these patients do suffer from three different diseases at the same time, the cirrhosis and the cancer.

In the past morbidity and mortality in cirrhosis were mainly determined by other complications of the disease, such as hepatic encephalopathy, upper digestive bleeding from esophageal varices, spontaneous bacterial peritonitis, hepatorenal syndrome. This is mainly due to both early diagnosis and optimized treatment of non-oncologic complications, that increasing life expectancy might be in parallel with the increasing incidence of $\mathrm{HCC}^{[6]}$. A significant cohort effect exists, as highest age-specific rates occur among persons aged 75 or older $^{[7]}$.

The most common causes of HCC in the Western countries are nonalcoholic fatty liver disease (NAFLD)/ NASH, HCV infection, followed by alcohol abuse, mixed viral hepatitis plus alcohol abuse, and HBV infection $^{[1,7-9]}$. Indeed, previous epidemiological studies have clearly shown that the prevalence and incidence of HCC significantly differ in developing countries vs. developed countries, as In Eastern Asia and Middle Africa the age-adjusted incidence rate ranges from 20 to 28 cases per 100,000 in men, while this is less than five per 100,000 in Northern Europe, Australia and America ${ }^{[10]}$. More in detail, among risk factors in western countries (Europe, America), HCV infection accounts for 60\%-70\%, HBV for 10\%-15\%, alcohol for 20\% and other risk factors (NASH, hemochromatosis, etc.) for the remaining 10\%. By contrast, in several areas of Asia and Africa, HBV infection is the higher risk factor (up to 70\%), while HCV, alcohol and NASH represent less than $10 \%-20 \%$.

The annual incidence of HCC in HBV cirrhotics exceeds $2 \%$, while in chronic carriers without cirrhosis the incidence varies between $0.4 \%$ and $0.6 \%$, according to gender, age, viral load, geographic area ${ }^{[8,11,12]}$. In patients with hepatitis $\mathrm{C}$ virus (HCV) infection the increased risk do coincide with the development of cirrhosis, when the yearly incidence varies between $3 \%$ and $8 \%^{[13-15]}$. In patients with genetic hemochromatosis the annual incidence of HCC following establishment of cirrhosis has been calculated to be up to $5 \%^{[3,16]}$. From a clinical point of view, it has been clearly shown that once the cause of liver damage has been removed, the incidence of HCC decreases, although it is not fully eliminated ${ }^{[8]}$.

\section{HBV AND HCC}

Although rather uncommon, HCC may develop in subjects with chronic HBV infection even in the absence of cirrhosis. In patients with HBV-related cirrhosis, the risk of HCC directly correlates with the degree of serum viral load (serum HBV DNA levels), with the adjusted hazard ratio higher in persons with HBV DNA $>10^{5} \mathrm{cp} / \mathrm{mL}$ than in those with HBV DNA levels $<10^{4} \mathrm{cp} / \mathrm{mL}$. It has been clearly shown that the eradication or suppression of the HBV replication by interferon or analogues nucleos(t)ides, significantly reduces, although not eliminate, the risk of HCC in patients with cirrhosis. Antiviral treatment also decreases the risk of hepatic events, liverrelated and all-cause mortality over a 5-year observation period, particularly among those with maintaned viral suppression ${ }^{[17-19]}$.

Several factors seem to increase HCC risk among HBV carriers: demographic (male gender, older age, ethnicity, family history of HCC), viral (high viral load, genotype, longer duration of infection, co-infection with HCV, HIV or HDV), clinical (cirrhosis) and environmental (exposure to aflatoxin, heavy alcohol abuse or cigarette smoking). It has been widely reported that chronically infected males have a higher risk of developing HCC if compared to females $(2: 1 \text { to } 3: 1)^{[20,21]}$ while in developed countries, HCC is rare in patients under 40 years ${ }^{[20]}$.

One could conclude that: (1) the natural history of chronic hepatitis B is dramatically improved by antiviral treatment; (2) prevention of HCC is not achieved in the absence of stable viral suppression; (3) patients with stable viral suppression show lower rates of hepatic decompensation as well as liver-related mortality and 
HCC incidence; and (4) maintained HBV DNA suppression does not fully eliminate the risk of HCC in patients with pre-existing cirrhosis ${ }^{[19]}$.

Several prediction models of hepatocellular carcinoma development in chronic HBV patients have been proposed. The PAGE-B score has been suggested for assessing HCC risk in HBV afflicted patients ${ }^{[20]}$.

\section{HCV AND HCC}

For whom it concerns the natural history of HCV-related cirrhosis, it has been clearly showed that the progression of chronic HCV hepatitis to cirrhosis is greatly influenced by the age of the patients: $5 \%$ of patients under 40 years and $20 \%$ of those over 40 years progress to cirrhosis in less than 20 years ${ }^{[20,22]}$. HCC risk in chronic HCV patients depends on the severity of fibrosis stage and the rate of progression is approximately $2 \%-6 \%$ per year. It has been established that HCV infected patients have a 15-20 fold risk of developing HCC compared with HCV negative patients ${ }^{[22]}$.

Previous papers reported that HCV patients achieving sustained virological response (SVR) have a significant reduction of life-threatening complications, such as liver failure and HCC. Cardoso et al. ${ }^{[23]}$ reported the cumulative incidence of HCC and of liver-related complications stratified according to the response to interferon (IFN) treatment, thus confirming that patients with SVR had a paramount reduction of the incidence of HCC with respect to those without SVR. These data were confirmed by Singal et al. ${ }^{[24]}$.

The recent development and widespread availability of the new DAAs of II generation have increased the rate of SVR up to $90 \%-95 \%$, rapidly decreasing the prevalence of HCV infection. Due to the lack of significant side effects, on the contrary of previous treatment with IFN plus ribavirin, also HCV patients with advanced liver disease or contraindications to IFN might receive this therapy. Although no adequate long-term followups are to date available, it is possible to predict that the incidence of HCC in HCV cirrhotic patients with stable viral eradication will greatly decrease in the next future ${ }^{[25]}$.

Development of HCV-related HCC in subjects with normal liver has been rarely reported ${ }^{[26,27]}$.

In conclusion, it is possible to affirm that: (1) in patients with chronic $\mathrm{C}$ hepatitis and cirrhosis no correlation exists between serum HCV RNA levels and the severity of the disease, in contrast with HBV-related disease ${ }^{[28]}$; (2) in patients with HCV cirrhosis, HCC development is significantly reduced in SVR, while no differences are seen between non responders and untreated people ${ }^{[23]}$; (3) prevention of HCC is not achieved in the absence of $\mathrm{SVR}^{[29-31]}$; (4) due to the paramount virological efficacy of the new DAAs it is possible to predict that in the next years the incidence in HCV cirrhosis will be dramatically reduced ${ }^{[32]}$.

\section{LIVER STEATOSIS AND HCC}

Fatty liver (NAFLD/NASH) and obesity at present represent the leading cause of HCC, at least in developed countries, probably becoming in the next future the main cause for developing $\mathrm{HCC}^{[1-4,33]}$. In comparison with the lot of papers on the prevalence of HCC in patients with HBV/HCV chronic infections, epidemiological data regarding the prevalence and incidence of HCC in patients with fatty liver are relatively scarce. A systematic review ${ }^{[34]}$ reported a prevalence of $0 \%-3 \%$ on a follow-up period between 5.6 and 21 years in the whole population of NAFLD/NASH people ${ }^{[6]}$. When only patients with steato-cirrhosis were considered, the incidence raise to $2.4 \%$ within a follow-up period of 7.2 years and $12.8 \%$ with a 3.2 -year follow-up ${ }^{[34]}$.

In a study of HCC management in a realworld setting, including 18,031 patients with HCC in 14 countries (2005-2012), NAFLD accounted for 10\%-12\% of underlying liver diseases in Europe and North America ${ }^{[35]}$. 
According to data from the Surveillance, Epidemiology and End Results (SEER)-Medicare linked database between 2004 and 2009, NAFLD represented the third most common cause of HCC, after hepatitis C and alcohol-related disease, diagnosed in $14.1 \%$ of patients with $\mathrm{HCC}^{[36]}$. During the six-year study period, an average annual increase of $9 \%$ was reported in patients with NAFLD, compared with a $13 \%$ increase in patients with hepatitis $C$.

In a United States population-based study, NAFLD was classified as the most common risk factor for the development of HCC (59\%) with a cumulative incidence of $0.3 \%$ over a 6 -year follow-up ${ }^{[37]}$. In another prospective community-based study which evaluated the outcomes of patients with NASH and cirrhosis, $11.3 \%$ of patients developed HCC after a mean follow-up of 7.6 years $^{[38]}$.

As to the prevalence of NAFLD in patients with HCC, several studies showed that steatosis at present does surpass $\mathrm{HCV}$ and $\mathrm{HBV}$ as the first cause of $\mathrm{HCC}$, ranging from $25 \%$ to $35 \%$ of all cases.

Moreover, other studies reported development of HCC in non cirrhotic NASH liver ${ }^{[39,40]}$. Thus, it is not surprising that NAFLD is the most rapidly increasing indication for liver transplantation (LT) due to HCC.

Beyond advanced liver disease itself $f^{[4]}$, several other factors might interact to increase the risk of HCC in patients with NAFLD, as follows: (1) type 2 diabetes; (2) obesity; (3) genetic background; and (4) co-factors (HBV, HCV, alcohol abuse).

\section{ALCOHOL AND HCC}

The relationship between alcohol-related cirrhosis and HCC is now well defined. Alcohol abuse is not only one relevant cause of chronic liver disease and cirrhosis, but strongly interacts with other causes of liver damage, such as HBV and HCV, worsening the progression of the disease and the development of HCC.

The risk of alcohol-related HCC depends upon several factors, as age, gender (more pronounced among females), duration and quantity of alcohol consumption. The 10-year cumulative risk of HCC in patients with alcoholic cirrhosis ranges from $7 \%$ to $30 \%{ }^{[42]}$.

Although quantity and duration of alcohol consumption have been associated with ALD progression ${ }^{[43]}$ and an increased risk for developing $\mathrm{HCC}^{[44]}$, not all patients who chronically overconsume alcohol develop alcoholic cirrhosis and/or HCC. Instead, progression to ALD is influenced by the interaction between consumption and a constellation of host factors, leading to the development of cirrhosis and HCC in only a subset of patients. In other words, although the threshold for development of alcohol-related chronic liver disease is well established ( $>30$ alcohol units for men and $>20$ alcohol units for women), it has not been yet defined the duration/quantity theshold above which the risk for HCC is strengthened ${ }^{[42]}$.

Probably, other factors might accelerate the progression toward the HCC: genetic factors, ethnicity, first-pass metabolism, volume of distribution, and gastric alcohol dehydrogenase kinetics.

\section{RISK OF HCC AND SURVEILLANCE}

According to International Guidelines ${ }^{[1,2,4,5,8]}$, several groups of patients are considered to have a higher risk of developing HCC, and in these people a strict 6-mo surveillance is mandatory, as follows: (1) cirrhotic patients of any etiology, regardless of Child-Pugh class; (2) non cirrhotic patients with chronic hepatitis B; (3) inactive hepatitis B carriers with viraemia > $2000 \mathrm{UI} / \mathrm{mL}$ (evidence $3 \mathrm{~b}$, strength B for Western patients; evidence $1 \mathrm{~b}$, strength $\mathrm{A}$ for Asian patients); (4) non cirrhotic patients with chronic hepatitis $\mathrm{C}$ and liver fibrosis $\geq$ F3 Metavir, or $\geq 10 \mathrm{kpa}$ at transient elastography (evidence 5, strength D for Western patients; 
Table 1. Comparison of demographic, clinical and US risk factors for HCC development

\begin{tabular}{lll}
\hline & Lower risk & Higher risk \\
\hline Gender & Female & Male \\
Age & $<50$ year & $>60$ year $^{\star}$ \\
Etiology & Single & Multiple \\
Co-factors & No & Yes \\
Child & A & B/C \\
US pattern & Fine & Coarse nodular \\
Macronodules & No & Yes \\
AFP & Normal & Increased \\
\hline
\end{tabular}

${ }^{\star}$ Asian, African (> 20-40 years). HCC: hepatocellular carcinoma

evidence 3b, strength B for Asian patients); and (5) successfully treated patients with chronic hepatitis B and C (undetectable viraemia), but belonging to any of the previous at risk categories prior to starting antiviral treatment.

The recently published American guidelines ${ }^{[8]}$ : (1) recommend surveillance of adults with cirrhosis because it improves overall survival (quality/certainty of evidence: moderate - strength of recommendation: strong); (2) suggest surveillance using ultra-sound (US), with or without alpha-fetoprotein (AFP), every 6 months (quality/certainty of evidence: low strength of recommendation: conditional); and (3) suggest not performing surveillance of patients with Child-Pugh class C cirrhosis unless they are on the transplant waiting list, given the low anticipated survival for these patients. (quality/certainty of the evidence: low strength of recommendation: conditional).

In conclusion, the lower risk for developing HCC on cirrhosis is seen in: (1) female gender; (2) age < 50 years; (3) fine US eco-pattern, no macronodules; (4) Child A class; and (5) normal alfa fetoprotein levels.

By contrast, patients at the higher risk of HCC show the following features: (1) male gender; (2) age > 60 years, long history of disease; (3) Asian, African (> 20-40 years); (4) Child B/C classes; (5) persistently high AFP; and (6) US-pattern "coarse nodular" [Table 1].

\section{CLINICAL ASPECTS}

The knowledge of the natural history of the disease and prognostic predictors is crucial to estimate the outcome of a given individual and the potential impact of conventional or investigational treatments, as well as to design prospective trials. Survival has improved because of the advancement of the time of diagnosis (lead-time bias) and the increase in the therapeutic efficacy ${ }^{[45]}$.

When managing HCC in cirrhotic patients, it should be considered that these people: (1) often are critically ill individuals; (2) often elderly; (3) may suffer from clinically relevant abnormalities of haemostasis, renal function and electrolyte balance; and (4) often suffer from systemic diseases (heart, lung).

Several clinical factors might increase mortality in these patients, thus worsening the natural history of the disease and hampering the possibility of effective treatments, such as extra hepatic diseases (lung, heart, kidney diseases), diabetes, obesity, etc.

It should be considered that cirrhotic patients often are elderly people, with a long history of disease. Furthermore, the relative risk of liver cancer ( $95 \%$ confidence interval) in obese elderly persons with BMI > $35 \mathrm{~kg} / \mathrm{m}^{2}$ has been calculated at 4.52 vs. 1.68 of all other cancer ${ }^{[46]}$. In these subjects, surveillance for HCC improves the survival of elderly cirrhotic patients by expanding the percentage of cancers amenable to 
effective treatments ${ }^{[47]}$. Several studies have shown that elderly patients with HCC have a worse prognosis compared to non-elderly ones, but such difference is not due to higher age, but rather seems to be the consequence of undertreatment ${ }^{[48]}$. In elderly patients undergoing treatment, survival was unaffected by $\operatorname{age}^{[49]}$.

From a clinical point of view, staging systems in HCC should define outcome prediction and treatment assignment. Due to the nature of HCC, the main prognostic variables are tumor stage, liver function and performance status ${ }^{[8]}$.

The most accepted clinical classification of HCC has been proposed by the Barcelona Clinic Liver Cancer ${ }^{[3]}$. The BCLC staging system has come to be widely accepted in clinical practice and is also being used for many clinical trials of new drugs to treat HCC. Therefore, it has become the de facto staging system that is used, and it was first endorsed by the EASL ${ }^{[s]}$, and thereafter by the AASLD guidelines for the management of $\mathrm{HCC}^{[3]}$.

This clinical classification does stratify patients with HCC into 5 different stages (stage 0 and stages A to D), according to the ECOG Performance Status (PST) and the Child Pugh Classification. Each stage is further subdivided according to four pre-established prognostic clinical and biochemical parameters (size of the nodule, number of nodules, portal pressure, bilirubin levels).

Beyond its clinical utility, the BCLC staging allows to allocate stage-specific treatment strategies and predicts expected survival.

In summary: (1) The main established parameters for the definition of the stage of HCC are: 1) tumor status; 2) number and size of nodules; 3) presence/absence of macrovascular invasion; 4) presence/absence of extraheaptic spread; 5) liver function; 6) Child-Pugh class; 7) serum bilirubin; 8) albumin levels; 9) presence/ absence of portal hypertension; 10) physical status; 11) ECOG classification; and 12) presence of symptoms; (2) prognosis prediction is defined by variables related to tumor status (size, number, vascular invasion, N1, M1), liver function (Child-Pugh's) and health status (Eastern Cooperative Oncology Group, ECOG); and (3) treatment allocation incorporates treatment dependant variables, which have been shown to influence therapeutic outcome, such as bilirubin, portal hypertension or presence of symptoms-ECOG.

The 5-stage classification ${ }^{[1,4-6]}$ categorizes patients into very early HCC (stage 0), early HCC (stage A), intermediate HCC (stage B), advanced HCC (stage C) and end-stage HCC (stage D).

Stage 0 - patients in the BCLC stage 0 are well-preserved liver function, belonging to the Child Pugh class A and with a performance status 0 . In this "very early" status there is a single nodule with size $<2 \mathrm{~cm}$ (or carcinoma in situ) without vascular invasion/satellites; portal pressure and bilirubin may be normal or increased. In the first case, patients are suitable for curative treatment as resection; on the contrary, if portal pressure and/or bilirubin levels are increased or extra-hepatic associated disease are present, resection might be contraindicated, and patients should undergo other curative treatments, such as liver transplantation, or local ablation with percutaneous ethanol injection (PEI) or radiofrequency ablation (RFA).

Stage A - patients in the BCLC stage A (early stage) show the following features: (1) single HCC nodule $>2$ $\mathrm{cm}$ but $<5 \mathrm{~cm}$, or three nodules $<3 \mathrm{~cm}$; (2) ECOG 0; (3) Child Pugh Class A or B; and (4) absence/presence of associated extra-hepatic diseases.

In the absence of associated diseases, the patients might be candidates to liver transplantation; otherwise, local ablation with PEI or RFA should be considered. Single tumors beyond $5 \mathrm{~cm}$ are still considered for 
surgical resection as first option, because if modern MRI is applied in pre-operative staging, the fact that solitary large tumors remain single and with no macrovascular involvement - which might be common in HBV-related HCC - reflects a more benign biological behaviour ${ }^{[8]}$.

Variables related to liver function are relevant for candidates to resection. Absence of clinically relevant portal hypertension and normal bilirubin are key predictors of survival in patients with single tumors undergoing resection ${ }^{[50,51]}$. Similarly, Child-Pugh class A is the strongest prognostic variable in patients undergoing local ablation, along with tumor size and response to treatment ${ }^{[50]}$. Since liver transplantation may potentially cure both the tumor and the underlying liver disease, variables mostly related with HCC have been clearly established as prognostic factors (single tumors $<5 \mathrm{~cm}$ or 3 nodules $<3 \mathrm{~cm}$ ), defining the so-called Milan criteria.

Stage B - patients in the intermediate stage B show multinodular asymptomatic HCC without an invasive pattern. Liver function may be preserved (Child A), or early decompensation might be seen (Child B). Performance Status is $=0$. These patients might receive a survival benefit from transarterial chemoembolization, while other treatments such PEI or RFA should be avoided.

Stage C - these subjects suffer from advanced HCC (N1, M1), that consists of macroscopic vascular invasion (portal vein invasion), extrahepatic spread (lymph nodes and metastasis) or cancer-related symptoms (performance status 1-2). They cannot receive treatments other than first line therapy with sorafenib.

Stage D - patients with terminal stage (stage D) have decompensed cirrhosis (Child C) and PST $>2$. Only supportive, symptomatic treatment can be offered.

\section{Prognosis and survival}

Due to the high clinical variability among the different stages of the BCLC classification, a significant difference in terms of survival exist.

Patients presenting with very early (stage 0) and early-stage diseases (stage A) represent 20\%-30\% of patients with HCC. This group, suitable for curative treatments such as resection, liver transplantation, or local ablation with PEI or RFA, have a 5-year survival of 50\%-70\%.

By contrast, patients in intermediate stage B and more advanced stage C stages, who account for 50\%-60\% of patients, have a poorer prognosis, presenting a 3-year overall survival of $10 \%-40 \%$. Finally, symptomatic subjects with end-stage disease (stage D; $10 \%-20 \%$ ) have a survival $<3$ months.

Several new tools will be available to identify cirrhotic patients at higher risk to develop HCC, such as DNA-fusion genes, genetic mutations and epigenetic changes, messenger RNA (mRNA), non-coding RNAincluding microRNAs (miRNA), long non-coding RNAs (lncRNA) and other species, proteins and posttranslational protein modifications (e.g., phosphorylation), metabolites and antibodies, AFP L3, des-gamma carboxy prothombin ${ }^{[8,52,53]}$. In the next future, these tools would be possible biomarkers for prognosis, diagnosis and as therapeutic targets for hepatocellular carcinoma.

\section{OPEN ISSUES AND CONCLUSIONS}

Despite substantial advancements in the knowledge and the management of patients with cirrhosis and HCC, several controversies and open issues exist, regarding the timing of surveillance, the optimal diagnostic tools, the increase of HCC after treatment with new DAAs, etc. ${ }^{[8]}$.

There is considerable debate regarding this latter issue. Indeed, two years ago, two papers from Spain and 
Italy suggested an unexpected high rate of early HCC recurrence in patients with HCV-related HCC treated with new DAAs ${ }^{[5,55]}$. There are several hypotheses as to why DAA treatment may lead to higher recurrence rates in HCC, one of which is that the activation of regeneration mechanisms through cure of inflammation could lead to growth of precancerous lesions. Another hypothesis involves the liver-specific microRNA 122, which reduces tumourigenesis, angiogenesis and intrahepatic metastasis, and is downregulated by DAA therapy $^{[56]}$.

Further papers do not confirm this suggestions, showing that DAA treatment is not associated with HCC recurrence after viral clearance in patients with HCV-related cirrhosis and previous history of HCC ${ }^{[57,58]}$.

Another issue to be further evaluated regards the diagnostic evaluation of suspected HCC with multiphasic CT or multiphasic MRI ${ }^{[8]}$. The AASLD recommends diagnostic evaluation for HCC with either multiphasic CT or multiphasic MRI because of similar diagnostic performance characteristics. The selection of the optimal modality and contrast agent for a particular patient depends on multiple factors beyond diagnostic accuracy. These include modality availability, scan time, through- put, scheduling backlog, institutional technical capability, examination costs and charges, radiologist expertise, patient preference, and safety considerations $^{[8]}$.

In conclusion, in the 21st century, HCC in patients with cirrhosis should be rather regarded as a preventable and treatable disease with current available treatments and not as the beginning of the end, leading inevitably to death. Diagnosis of HCC at present no more implies a "Chronicle of a death foretold".

\section{DECLARATIONS}

\section{Authors' contributions}

The author contributed solely to the article.

\section{Availability of data and materials}

Not applicable.

\section{Financial support and sponsorship}

None.

\section{Conflicts of interest}

The author declared that there are no conflicts of interest.

\section{Ethical approval and consent to participate}

Not applicable.

\section{Consent for publication}

Not applicable.

\section{Copyright}

(c) The Author(s) 2018.

\section{REFERENCES}

1. Italian Association for the Study of the Liver (AISF). Position paper of the Italian Association for the Study of the Liver (AISF): the multidisciplinary clinical approach to hepatocellular carcinoma. Digest Liver Dis 2013;45:712-23.

2. European association for the study of the liver, European organisation for research and treatment of cancer EASL-EORTC clinical practice guidelines: management of hepatocellular carcinoma. J Hepatol 2012;56:908-43. 
3. Ružić M, Pellicano R, Fabri M, Luzza F, Boccuto L, Brkić S, Abenavoli L. Hepatitis C virus-induced hepatocellular carcinoma: a narrative review. Panminerva Med 2018; doi: 10.23736/S0031-0808.

4. Bruix J, Sherman M. Management of hepatocellular carcinoma. Hepatology 2011;53:1020-2.

5. Cabrera R, Nelson DR. The management of hepatocellular carcinoma. Aliment Pharmacol Ther 2010;31:461-76.

6. Sangiovanni A, Prati GM, Fasani P, Ronchi G, Romeo R, Manini M, Del Ninno E, Morabito A, Colombo M. The natural history of compensated cirrhosis due to hepatitis C virus: a 17-year cohort study of 214 patients. Hepatology 2006;43:1303-10.

7. Chacko S, Samanta S. Hepatocellular carcinoma: a life-threatening disease. Biomed Pharmacother 2016;84:1679-88.

8. Heimbach JK, Kulik LM, Finn RS, Sirlin CB, Abecassis MM, Roberts LR, Zhu AX, Murad MH, Marrero JA. AASLD Guidelines for the treatment of hepatocellular carcinoma. Hepatology 2018;67:358-80.

9. Santi V, Buccione D, Di Micoli A, Fatti G, Frigerio M, Farinati F, Del Poggio P, Rapaccini G, Di Nolfo MA, Benvegnù L, Zoli M, Borzio F, Giannini EG, Caturelli E, Chiaramonte M, Bernardi M, Trevisani F. The changing scenario of hepatocellular carcinoma over the last two decades in Italy. J Hepatol 2012;56:397-405.

10. Parkin DM, Bray F, Ferlay J, Pisani P. Global cancer statistics, 2002. CA Cancer J Clin 2005;55:74-108.

11. Ioannou G, Splan M, Weiss N, McDonald G, Beretta L, Lee S. Incidence and predictors of hepatocellular carcinoma in patients with cirrhosis. Clin Gastroenterol Hepatol 2007;5:938-45.

12. Lok AS, Seeff LB, Morgan TR, Di Bisceglie AM, Sterl ng RK, Curto TM, Everson GT, Lindsay KL, Lee WM, Bonkovs.ky HL, Dienstag JL, Ghany MG, Morishima C, Goodman ZD; HALT-C Trial Group. Incidence of hepatocellular carcinoma and associated risk factors in hepatitis C-related advanced liver disease. Gastroenterology 2009;136:138-48.

13. Masuzaki R, Tateishi R, Yoshida H, Goto E, Sato T, Ohki T. Prospective risk assessment for hepatocellular carcinoma development in patients with chronic hepatitis C by transient elastography. Hepatology 2009;49:1954-61.

14. Jung KS, Kim SU, Ahn SH, Park YN, Kim do Y, Park JY, Chon CY, Choi EH, Han KH. Risk assessment of hepatitis B virus-related hepatocellular carcinoma development using liver stiffness measurement (FibroScan). Hepatology 2011;53:885-94.

15. Lok AS. Prevention of hepatitis B virus-related hepatocellular carcinoma. Gastroenterology 2004;127:S303-9.

16. Deugnier YM, Guyader D, Crantock L, Lopez JM, Turlin B, Yaouanq J. Primary liver cancer in genetic hemochromatosis: a clinical, pathological, and pathogenetic study of 54 cases. Gastroenterology 1993;104:228-34.

17. Chen CJ, Yang HI, Su J, Jen CL, You SL, Lu SN, Huang GT, Iloeje UH; REVEAL-HBV Study Group. REVEAL-HBV Study Group. Risk of hepatocellular carcinoma across a biological gradient of serum hepatitis B virus DNA level. JAMA 2006;295:65-73.

18. Yu MW, Yeh SH, Chen PJ, Liaw YF, Lin CL, Liu CJ, Shih WL, Kao JH, Chen DS, Chen CJ. Hepatitis B virus genotype and DNA level and hepatocellular carcinoma: a prospective study in men. J Natl Cancer Inst 2005;97:265-72.

19. Iloeje UH, Yang HI, Su J, Jen CL, You SL, Chen CJ. Risk evaluation of viral load elevation and associated liver disease/cancer-In HBV (the REVEAL-HBV) study group. Predicting cirrhosis risk based on the level of circulating hepatitis B viral load. Gastroenterology 2006;130:678-86.

20. Papatheodoridis G, Dalekos G, Sypsa V, Yurdaydin C, Buti M, Goulis J, Calleja JL, Chi H, Manolakopoulos S, Mangia G, Gatselis N, Keskin O, Savvidou S, de la Revilla J, Hansen BE, Vlachogiannakos I, Galanis K, Idilman R, Colombo M, Esteban R, Janssen HL, Lampertico P. PAGE-B predicts the risk of developing hepatocellular carcinoma in Caucasians with chronic hepatitis B on 5-year antiviral therapy. J Hepatol 2016;64:800-6.

21. Kew MC. Epidemiology of chronic hepatitis B virus infection, hepatocellular carcinoma, and hepatitis B virus-induced hepatocellular carcinoma. Pathol Biol 2010;58:273-7.

22. Blachier M, Leleu H, Peck-Radosavljevic M, Valla DC, Roudot-Thorav F. The burden of liver disease in Europe: a review of available epidemiological data. J Hepatol 2013;58:593-608.

23. Cardoso AC, Moucari R, Figueiredo-Mendes C, Ripault MP, Giuily N, Castelnau C, Boyer N, Asselah T, Martinot-Peignoux M, Maylin S, Carvalho-Filho RJ, Valla D, Bedossa P, Marcellin P. Impact of peginterferon and ribavirin therapy on hepatocellular carcinoma: incidence and survival in hepatitis C patients with advanced fibrosis. J Hepatol 2010;52:652-7.

24. Singal AG, Volk ML, Jensen D, Di Bisceglie AM, Schoenfeld PS. A sustained viral response is associated with reduced liver-related morbidity and mortality in patients with hepatitis C virus. Clin Gastroenterol Hepatol 2010;8:280-8.

25. Axley P, Ahmed Z, Ravi S, Singal AK. Hepatitis C virus and hepatocellular carcinoma: a narrative review. J Clin Transl Hepatol 2018;6:7984.

26. Puoti C, Bellis L, Martellino F, Durola L, Spilabotti L, Dell'Unto O. Occurrence of hepatocellular carcinoma in an apparently 'healthy' HCV patient. Eur J Gastroenterol Hepatol 2005;17:1263-4.

27. Puoti C, Lanzetta G, Scotti E. Occurrence of hepatocellular carcinoma 13 years after successful antiviral treatment for HCV infection. J Gastrointestin Liver Dis 2016;25:408-9.

28. Puoti C, Stati T, Magrini A. Serum HCV RNA titer does not predict the severity of liver damage in HCV carriers with normal aminotransferase levels. Liver 1999;19:104-9.

29. Bruno S, Di Marco V, Iavarone M, Roffi L, Boccaccio V, Crosignani A, Cabibbo G, Rossi S, Calvaruso V, Aghemo A, Giacomelli L, Craxì A, Colombo M, Maisonneuve P. Improved survival of patients with hepatocellular carcinoma and compensated hepatitis C virus-related cirrhosis who attained sustained virological response. Liver Int 2017;37:1526-34.

30. Morgan RL, Baack B, Smith BD, Yartel A, Pitasi M, Falck-Ytter Y. Eradication of hepatitis C virus infection and the development of hepatocellular carcinoma: a meta-analysis of observational studies. Ann Intern Med 2013;158:329-37.

31. Nahon P, Bourcier V, Layese R, Audureau E, Cagnot C, Marcellin P, Guyader D, Fontaine H, Larrey D, De Lédinghen V, Ouzan D, Zoulim F, Roulot D, Tran A, Bronowicki JP, Zarski JP, Leroy V, Riachi G, Calès P, Péron JM, Alric L, Bourlière M, Mathurin P, Dharancy S, Blanc JF, Abergel A, Serfaty L, Mallat A, Grangé JD, Attali P, Bacq Y, Wartelle C, Dao T, Benhamou Y, Pilette C, Silvain C, Christidis C, Capron D, Bernard-Chabert B, Zucman D, Di Martino V, Thibaut V, Salmon D, Ziol M, Sutton A, Pol S, Roudot-Thoraval F; ANRS CO12 CirVir Group. Eradication of hepatitis C virus infection in patients with cirrhosis reduces risk of liver and non-liver complications. 
Gastroenterology 2017;152:142-56.

32. Andreoni M, Babudieri S, Bruno S, Colombo M, Zignego AL, Di Marco V, Di Perri G, Perno CF, Puoti M, Taliani G, Villa E, Craxì A. Current and future challenges in HCV: insights from an Italian experts panel. Infection 2018;46:147-63.

33. Younes R, Bugianesi E. Should we undertake surveillance for HCC in patients with NAFLD? J Hepatol 2018;8:326-34.

34. White DL, Kanwal F, El-Serag HB. Association Between nonalcoholic fatty liver disease and risk for hepatocellular cancer, based on systematic review. Clin Gastroenterol Hepatol 2012;10:1342-59.

35. Park JW, Chen M, Colombo M, Roberts LR, Schwartz M, Chen PJ, Kudo M, Johnson P, Wagner S, Orsini LS, Sherman M. Global patterns of hepatocellular carcinoma management from diagnosis to death: the BRIDGE study. Liver Int 2015;35:2155-66.

36. Younossi ZM, Otgonsuren M, Henry L, Venkatesan C, Mishra A, Erario M. Association of nonalcoholic fatty liver disease (NAFLD) with hepatocellular carcinoma (HCC) in the United States from 2004 to 2009. Hepatology 2015;62:1723-30.

37. Sanyal A, Poklepovic A, Moyneur E, Barghout V. Population-based risk factors and resource utilization for HCC: US perspective. Curr Med Res Opin 2010;26:2183-91.

38. Yatsuji S, Hashimoto E, Tobari M, Taniai M, Tokushige K, Shiratori K. Clinical features and outcomes of cirrhosis due to nonalcoholic steatohepatitis compared with cirrhosis caused by chronic hepatitis C. J Gastroenterol Hepatol 2009;24:248-54.

39. Donati B, Dongiovanni P, Romeo S, Meroni M, McCain M, Miele L, Petta S, Maier S, Rosso C, De Luca L, Vanni E, Grimaudo S, Romagnoli R, Colli F, Ferri F, Mancina RM, Iruzubieta P, Craxi A, Fracanzani AL, Grieco A, Corradini SG, Aghemo A, Colombo M, Soardo G, Bugianesi E, Reeves H, Anstee QM, Fargion S, Valenti L. MBOAT7 rs641738 variant and hepatocellular carcinoma in noncirrhotic individuals. Sci Rep 2017;7:4492.

40. Mohamad B, Shah V, Onyshchenko M, Elshamy M, Aucejo F, Lopez R, Hanouneh IA, Alhaddad R, Alkhouri N. Characterization of hepatocellular carcinoma (HCC) in non-alcoholic fatty liver disease (NAFLD) patients without cirrhosis. Hepatol Int 2016;10:632-9.

41. Puoti C, Elmo MG, Ceccarelli D, Ditrinco M. Liver steatosis: the new epidemic of the third millennium. Benign liver state or silent killer? Eur J Intern Med 2017;46:1-5.

42. Joshi K, Kohli A, Manch R, Gish R. High risk or low risk for developing hepatocellular carcinoma? Clin Liver Dis 2016;20:563-80.

43. Teli MR, Day CP, Burt AD, Bennett MK, James OF. Determinants of progression to cirrhosis or fibrosis in pure alcoholic fatty liver. Lancet 1995;346:987-90.

44. Bagnardi V, Blangiardo M, La Vecchia C, Corrao G. A meta-analysis of alcohol drinking and cancer risk. Br J Cancer 2001;85:1700-5.

45. Bruix J, Sherman M, Llovet JM, Beaugrand M, Lencioni R, Burroughs AK, Christensen E, Pagliaro L, Colombo M, Rodés J; EASL Panel of Experts on HCC. Clinical management of hepatocellular carcinoma. J Hepatol 2001;35:421-30.

46. Calle EE, Rodriguez C, Walker-Thurmond K, Thun MJ. Overweight, obesity, and mortality from cancer in a prospectively studied cohort of U.S. adults. N Engl J Med 2003;24:1625-38.

47. Santi V, Trevisani F, Gramenzi AL, Grignaschi A, Milici-Cappa F, Del Poggio P, Di Nolfo MA, Benvegnù L, Farinati F, Zoli M, Giannini EG, Borzio F, Caturelli E, Chiaramonte M, Bernardi M; Italian liver cancer (ITA.LI.CA) group. Semiannual surveillance is superiore to annual surveillance for the detection of early hepatocellular carcinoma and patient survival. J Hepatol 2010;53:291-7.

48. Pignata S, Gallo C, Daniele B, Elba S, Giorgio A, Capuano G. Characteristics at presentation and outcome of hepatocellular carcinoma (HCC) in the elderly. A study of the cancer of the liver Italian program (CLIP). Crit Rev Oncol Hematol 2006;59:243-9.

49. Mirici-Cappa F, Gramenzi A, Santi V, Zambruni A, Di Micoli A, Frigerio M, Maraldi F, Di Nolfo MA, Del Poggio P, Benvegnù L, Rapaccini G, Farinati F, Zoli M, Borzio F, Giannini EG, Caturelli E, Bernardi M, Trevisani F; Italian Liver Cancer Group. Treatments for hepatocellular carcinoma in elderly patients are as effective as in younger patients. Gut 2010;59:387-96.

50. Llovet JM, Fuster J, Bruix J. Intention-to-treat analysis of surgical treatment for early hepatocellular carcinoma: resection versus transplantation. Hepatology 1999;30:1434-40.

51. Sala M, Llovet JM, Vilana R, Bianchi L, Solé M, Ayuso C. Barcelona Clínic Liver Cancer Group. Initial response to percutaneous ablation predicts survival in patients with hepatocellular carcinoma. Hepatology 2004;40:1352-60.

52. Tian YW, Shen Q, Jiang QF, Wang YX, Li K, Xue HZ. Decreased levels of miR-34a and miR-217 act as predictor biomarkers of aggressive progression and poor prognosis in hepatocellular carcinoma. Minerva Med 2017;108:108-13.

53. Chaiteerakij R, BD, Roberts LF. Update on biomarkers for hepatocellular carcinoma. Clin Gastroenterol Hepatol 2015;13:237-45.

54. Reig M, Marino Z, Perello C, Inarrairaegui M, Ribeiro A, Lens S, Díaz A, Vilana R, Darnell A, Varela M, Sangro B, Calleja JL, Forns X, Bruix J. Unexpected early tumor recurrence in patients with hepatitis $\mathrm{C}$ virus - related hepatocellular carcinoma undergoing interferon-free therapy: a note of caution. J Hepatol 2016;65:719-26.

55. Conti F, Buonfiglioli F, Scuteri A, Crespi C, Bolondi L, Caraceni P, Foschi FG, Lenzi M, Mazzella G, Verucchi G, Andreone P, Brillanti S. Early occurrence and recurrence of hepatocellular carcinoma in HCV-related cirrhosis treated with direct acting antivirals. J Hepatol 2016;65:727-33.

56. Nault JC, Colombo M. Hepatocellular carcinoma and direct acting antiviral treatments: controversy after the revolution. J Hepatol 2016;65:663-5.

57. Kanwal F, Kramer J, Asch SM, Chayanupatkul M, Cao Y, El-Serag HB. Risk of hepatocellular cancer in HCV patients treated with directacting antiviral agents. Gastroenterology 2017;153:996-1005.

58. Waziry R, Hajarizadeh B, Grebely J, Amin J, Law M, Danta M, George J, Dore GJ. Hepatocellular carcinoma risk following direct-acting antiviral HCV therapy: a systematic review, meta-analyses, and meta-regression. J Hepatol 2017;67:1204-12. 